\title{
Morphology of posterior segment lesions of the eye in patients with onchocerciasis
}

\author{
A. C. BIRD†, J. ANDERSON*, AND H. FUGLSANG* \\ From the Institute of Ophthalmology and Moorfields Eye Hospital $\uparrow$, and the \\ Medical Research Council, Kumba, United Cameroon Republic*
}

Hissette (1932), Bryant (1935), and Ridley (1945) described ocular fundus changes in Central Africa which were characterized by atrophy of the pigment epithelium and choroid, and they suggested that there was an association between these lesions and infection with Onchocerca volvulus. More recent epidemiological and histopathological evidence supports the causal nature of this association (Rodger, 1960; Budden, 1963; Monjusiau, Lagraulet, D'Haussy, and Göckel, 1965; Anderson, Fuglsang, Hamilton, and Marshall, I974a). Many authors, including Quevedo (194I), Clark (1947), Toulant, Robineau, and Puyelo (1950), D'Haussy, Rit, and Lagraulet (1958), and Lagraulet and Monjusiau (1964), have also recognized that optic neuritis and optic atrophy are associated with onchocerciasis. However, the pathogenesis of the posterior segment lesions remains obscure (Rodger, 1960; Budden, 1962; Quéré, Basset, Larivière, Basset, and Razafinjato, 1963; Ben-Sira and Yassur, 1972), and little attention has been given to the relative importance of optic nerve and fundus lesions as causes of blindness in onchocerciasis (D'Haussy, Boithias, and Bertet, 1954; Weyts, 1956).

The morphology of the posterior segment lesions attributable to onchocerciasis in 244 patients who were examined in the Sudan-savanna and rainforest zones of the United Cameroon Republic is described in this paper. The study took place in March 1974 and March 1975.

\section{Materials and methods}

Altogether 33I patients were selected for examination from three sources:

(a) 85 had posterior segment lesions compatible with onchocerciasis which had been identified during a population survey carried out in 1970-72 (Anderson and others, 1974a; Anderson, Fuglsang, Hamilton, and Marshall, 1974b).

* Medical Research Council Grant holders, PO Box 55, Kumba, SW Province, United Cameroon Republic

This study was supported by the Medical Research Council

Address for reprints: A. C. Bird, FRCS, Moorfields Eye Hospital, City Road, London ECr (b) 23 I patients, most of whom had come spontaneously with visual complaints, were found to be heavily infected with $O$. volvulus.

(c) 15 patients were from the Bulu Blind School in the SW Province of Cameroon.

Eighty-seven patients from groups (b) and (c) were rejected from the study. In 56 , the fundus was considered to be normal and no evidence of visual loss was detected, and in 31 there were fundus lesions unrelated to onchocerciasis - such as typical ocular toxoplasmosis, myopia, macular hole, and genetically-determined retinitis pigmentosa.

This report is concerned with the findings in the remaining 244 patients.

Of these, I 40 came from the Sudan-savanna and I04 from the rain-forest. Of the I40 savanna patients, $5^{8}$ had previously received treatment with suramin and/or diethylcarbamazine citrate (dec) under medical supervision. In the rain-forest, nine of the 104 patients had been treated similarly, and many others admitted to having taken variable quantities of dec on their own initiative.

The intensity of infection with $O$. volvulus had been assessed previously by measuring the concentration of microfilariae in weighed skin snips, and by recording the number of microfilariae seen in the cornea and anterior chamber, together with their presence in the retrolental space or vitreous (Anderson and others, 1974a).

Visual acuity was measured using the illiterate Echart, and visual fields to confrontation were recorded in most patients. After the pupil had been dilated with mydriacil I per cent, the fundus was examined by indirect and direct ophthalmoscopy, and colour photographs were taken using a Kowa RC 2 fundus camera. Fluorescein angiography was performed in 210 patients. Five $\mathrm{ml} 20$ per cent sodium fluorescein were injected into the antecubital vein, and photographs were taken, with a Kowa $\mathrm{RC} 2$ fundus camera, at $\mathrm{I} \cdot 5 \mathrm{~s}$ intervals during the initial transit of dye through the retinal vessels, and subsequently at $\mathrm{r}, 3$, and $5 \mathrm{~min}$. A Baird Atomic filter with an 80 per cent transmission at $4800 \AA$ and a broad transmission band of $400 \AA$ was used for excitation, and an Ilford 1 ro Gelatin filter as a barrier.

Blood specimens were obtained from 95 patients who had undergone angiography in 1974. Dr Pauline O'Neill of the Department of Clinical Microbiology, Louis Jenner Laboratories, St Thomas's Hospital, London SEI, performed Treponema pallidum haemag- 
glutination (TPHA) tests and Venereal Disease Reference Laboratory (VDRL) slide tests for anticardiolipin antibody on the specimens. Solubility tests for sickle haemoglobin were performed by Professor R. G. Huntsman in the Department of Pathology, Lambeth Hospital, London SEI, and haemoglobin electrophoresis was done by Dr S. Welch in the Department of Biochemistry, London Hospital Medical College, London Er.

\section{Results}

Table I shows the age and sex distribution of the 244 patients. Relatively more young males were included in the savanna, but the male/female ratio was the same in both areas (approximately $5: 1)$.

In the 140 savanna patients the pretreatment mean numbers of microfilariae per $\mathrm{mg}$ of skin $(\mathrm{mf} / \mathrm{mg})$ at the left outer canthus, shoulder, buttock, and calf, were $32,45,120$, and 95 respectively. In only five of them was the skin concentration less than $50 \mathrm{mf} / \mathrm{mg}$ at all four sites; two were old men, one was a boy aged 6 years, and in the other two there was a doubtful history of previous treatment. The savanna patients were thus shown to be heavily infected. Microfilariae were seen in the cornea in 134 of the 140 patients ( 95.7 per cent). In 22 patients $1-5$ microfilariae were present, in 29 6-20, and in 83 more than 20 microfilariae. Microfilariae were also seen in the anterior chamber in 120 patients $(85.7$ per cent) at a single pretreatment examination ( $\mathrm{I}-5$ microfilariae in 75 patients, $6-20$ in 28 , and over 20 in 17 ). Microfilariae were seen in the retrolental space or in the vitreous in 47 of the 140 cases (33.6 per cent).

Valid pre-treatment microfilarial density figures were available from only 52 of the 104 rain-forest patients, and skin snips had not been taken at the outer canthus and calf. The mean number of $\mathrm{mf} / \mathrm{mg}$ was 42 at the shoulder and 124 at the

Table I Age and sex distribution by area

\begin{tabular}{|c|c|c|c|c|c|c|c|c|}
\hline \multirow[b]{3}{*}{$\begin{array}{l}\text { Age } \\
\text { (yrs) }\end{array}$} & \multicolumn{4}{|c|}{ Savanna } & \multicolumn{4}{|c|}{ Rain-forest } \\
\hline & \multicolumn{2}{|c|}{ Males } & \multicolumn{2}{|c|}{ Females } & \multicolumn{2}{|c|}{ Males } & \multicolumn{2}{|c|}{ Females } \\
\hline & No. & $\begin{array}{l}\text { (Per } \\
\text { cent })\end{array}$ & No. & $\begin{array}{l}\text { (Per } \\
\text { cent })\end{array}$ & No & $\begin{array}{l}\text { (Per } \\
\text { cent })\end{array}$ & No. & $\begin{array}{l}\text { (Per } \\
\text { cent })\end{array}$ \\
\hline 5-9 & 3 & (2) & I & (I) & I & (I) & 0 & (o) \\
\hline $10-19$ & $4 I$ & (29) & 7 & (5) & 8 & $(8)$ & 3 & (3) \\
\hline $20-29$ & 32 & (23) & I I & (8) & 16 & (15) & 4 & (4) \\
\hline $30-39$ & 23 & (16) & 6 & (4) & 20 & (19) & 5 & (5) \\
\hline $40-49$ & 8 & (6) & 5 & (4) & 26 & (25) & 5 & (5) \\
\hline $50+$ & 3 & (2) & 0 & (o) & I6 & (15) & 0 & (o) \\
\hline Total & 110 & (79) & 30 & $(2 I)$ & 87 & $(84)$ & 17 & (16) \\
\hline
\end{tabular}

Table II Pattern of ocular disease (shown as a percentage of the population studied)

\begin{tabular}{|c|c|c|c|}
\hline & & Savanna & $\begin{array}{l}\text { Rain- } \\
\text { forest }\end{array}$ \\
\hline Morphology & $\begin{array}{l}\text { Retinal pigment } \\
\text { epithelial atrophy } \\
\text { mild } \\
\text { severe } \\
\text { Atrophy of retina } \\
\text { and } \\
\text { choriocapillaris } \\
\text { Ill-defined sub- } \\
\text { retinal swelling } \\
\text { Subretinal fibrosis }\end{array}$ & $\begin{array}{l}20 \cdot 7 \\
36 \cdot 4 \\
20.7 \\
5.7 \\
6.4\end{array}$ & $\begin{array}{r}25 \cdot 0 \\
40 \cdot 4 \\
20 \cdot 2 \\
5 \cdot 8 \\
11 \cdot 5\end{array}$ \\
\hline Distribution & $\begin{array}{l}\text { Temporal } \\
\text { Nasal } \\
\text { Peripapillary }\end{array}$ & $\begin{array}{r}54 \cdot 3 \\
7 \cdot 1 \\
10 \cdot 0\end{array}$ & $\begin{array}{r}56 \cdot 7 \\
7 \cdot 7 \\
7 \cdot 7\end{array}$ \\
\hline $\begin{array}{l}\text { Optic } \\
\text { nerve } \\
\text { disease }\end{array}$ & $\begin{array}{l}\text { Optic atrophy } \\
\text { Pronounced sheath- } \\
\text { ing of vessels } \\
\text { Swelling of optic } \\
\text { disc }\end{array}$ & $\begin{array}{r}55 \cdot 7 \\
13 \cdot 6 \\
26 \cdot 4\end{array}$ & $\begin{array}{r}67 \cdot 3 \\
19 \cdot 2 \\
\mathbf{I} \cdot 5\end{array}$ \\
\hline
\end{tabular}

buttock. Microfilariae were seen in the cornea in 33 of these 52 patients $(63.5$ per cent), $1-5$ in 18 cases, 6-20 in II, and more than 20 in four. They were seen in the anterior chamber in 46 patients (88.5 per cent), $I-5$ in $21,6-20$ in 12 , and more than 20 in 13 , and in the retrolental space or vitreous in $22(42 \cdot 3$ per cent $)$.

In this selected group there were thus relatively more savanna patients showing microfilariae in the cornea, whereas relatively fewer showed them in the anterior chamber and posterior to the lens.

Since the pattern of posterior segment lesions was similar in both sexes and in treated and untreated patients, the ocular analysis is given by area only. Fundus lesions were analysed in terms of their morphology and distribution, and the relative frequency of the different forms and of the severity of the fundus disease were summarized by area (Table II). The changes in the optic discs were analysed, and the relative contribution to reduction of visual acuity of choroido-retinal and optic nerve lesions was also assessed.

\section{CHOROIDO-RETINAL CHANGES}

Many of the fundi presented a polymorphic appearance, and it was common to observe lesions of different appearance in the same fundus. Within individual lesions, one part often presented a different appearance from another. The morphology and distribution of the choroido-retinal lesions 


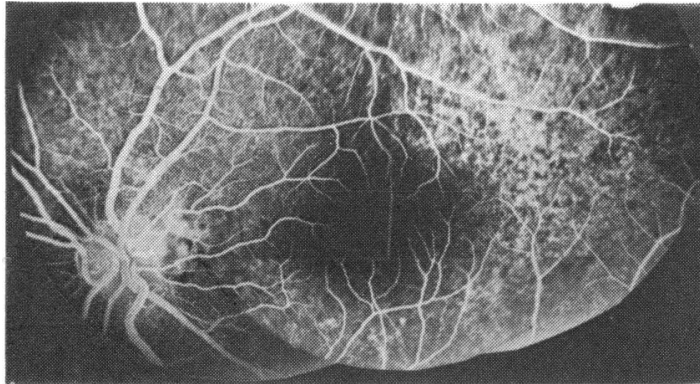

FIG. I Irregular atrophy of pigment epithelium temporal to fovea giving rise to mottled hyperfuorescence during fluorescein fundus angiography

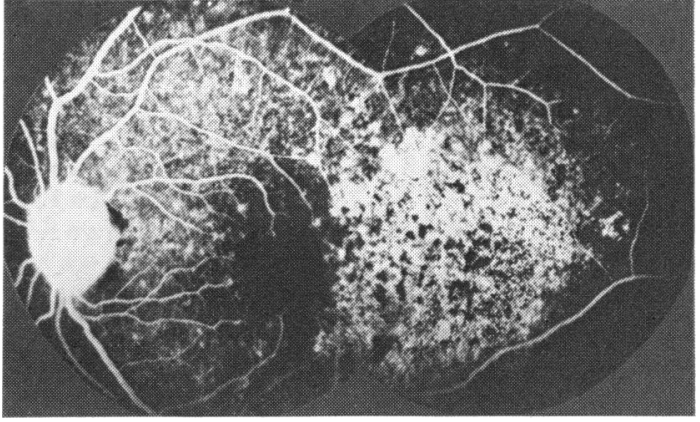

FIG. 2 Confluent atrophy of pigment epithelium temporal to fovea shown as transmission defect

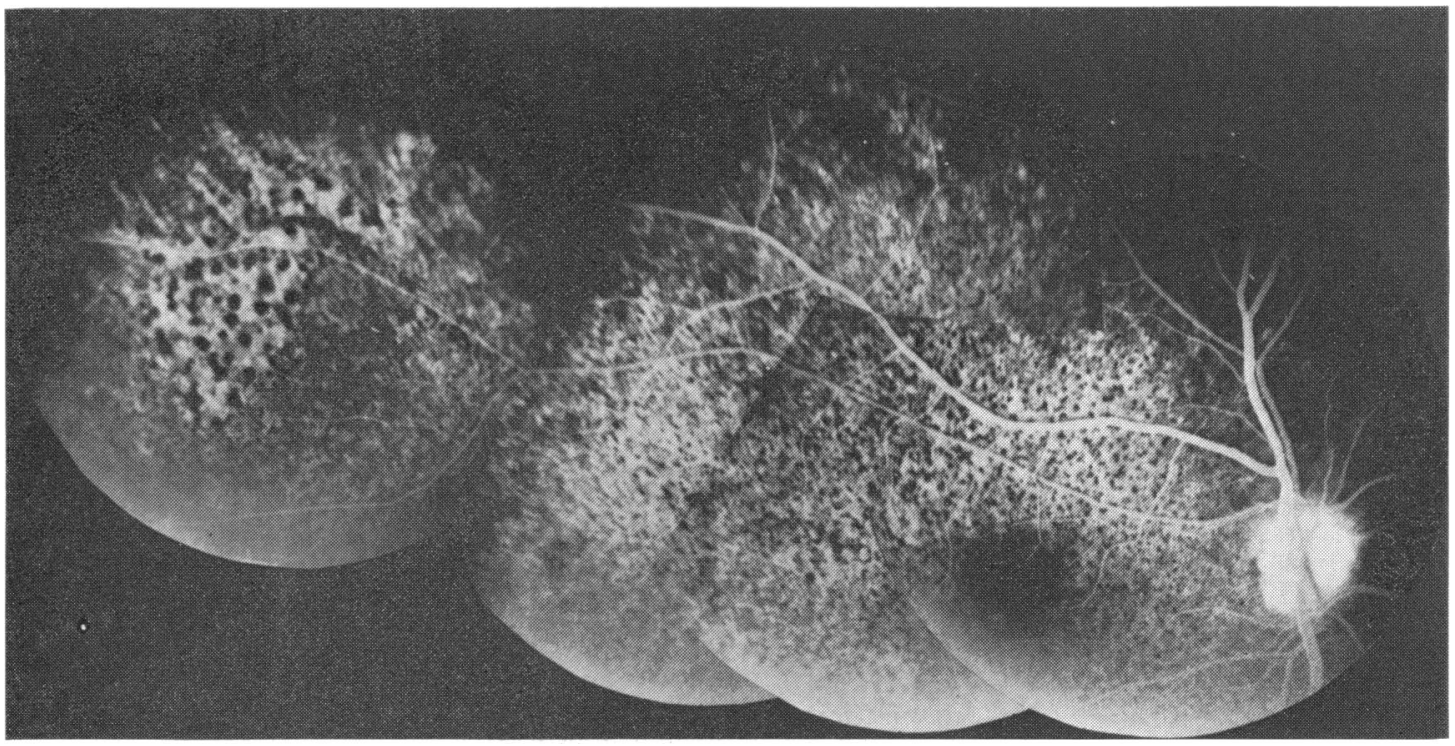

FIG. 3 Confluent atrophy of pigment epithelium extending from optic disc upper temporally with evenly distributed punctate hyperpigmentation throughout lesion. Leakage of dye from optic disc also occurred

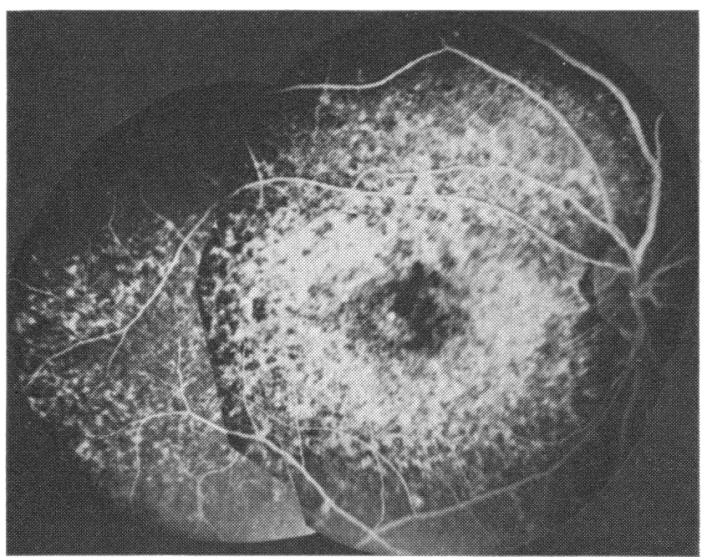

FIG. 4 Confluent atrophy of pigment epithelium surrounding fovea

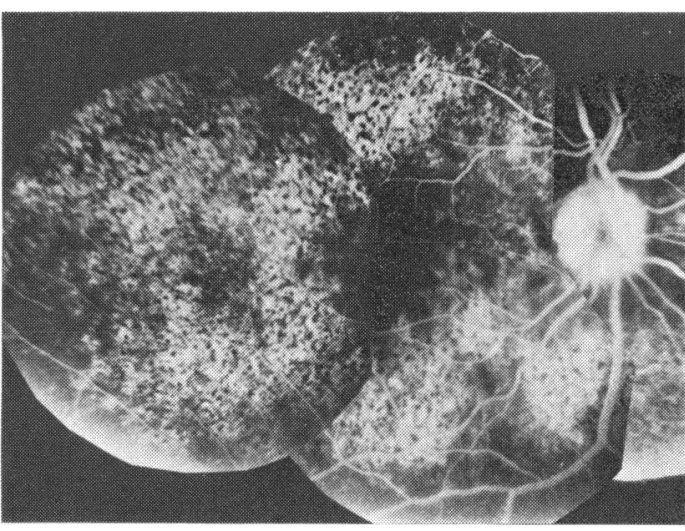

FIG. 5 Confluent atrophy of pigment epithelium occupying whole of posterior pole with leakage of dye from optic disc 


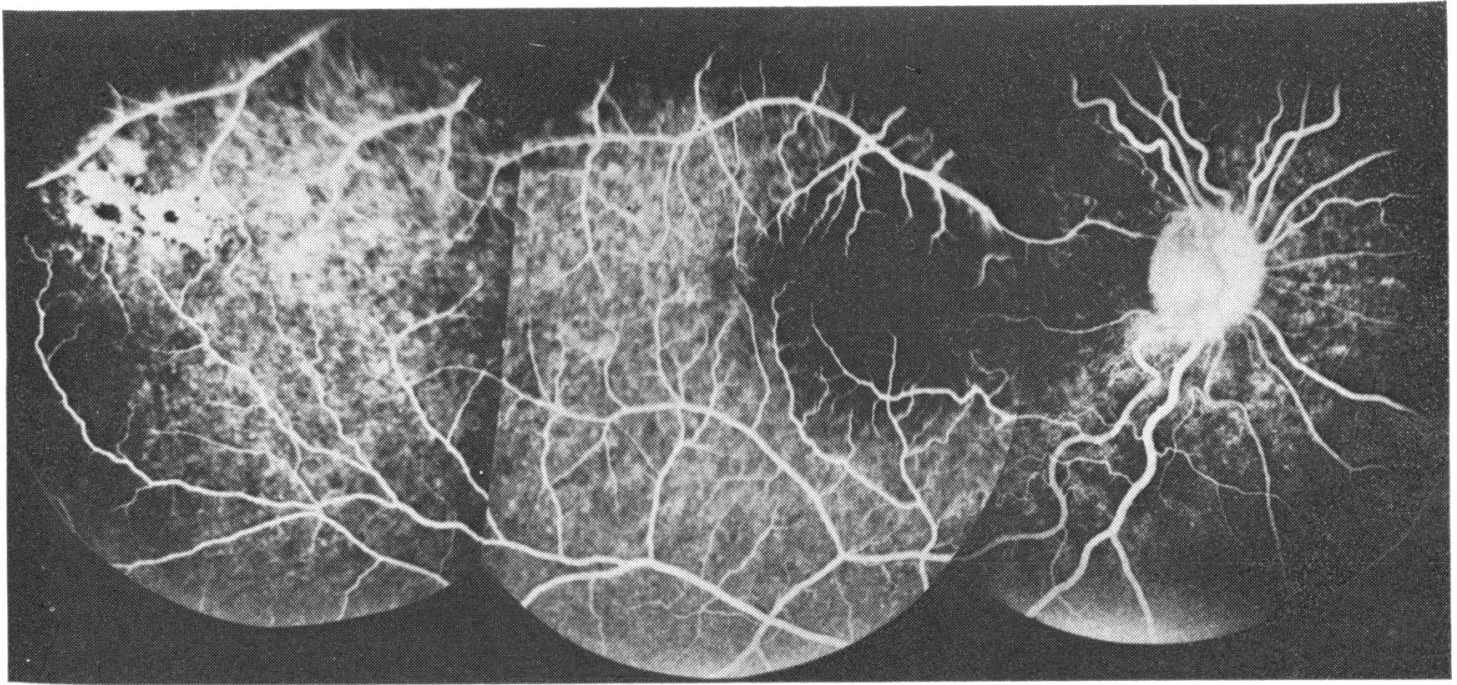

FIG. 6 Isolated temporal lesion with leakage of dye from optic disc

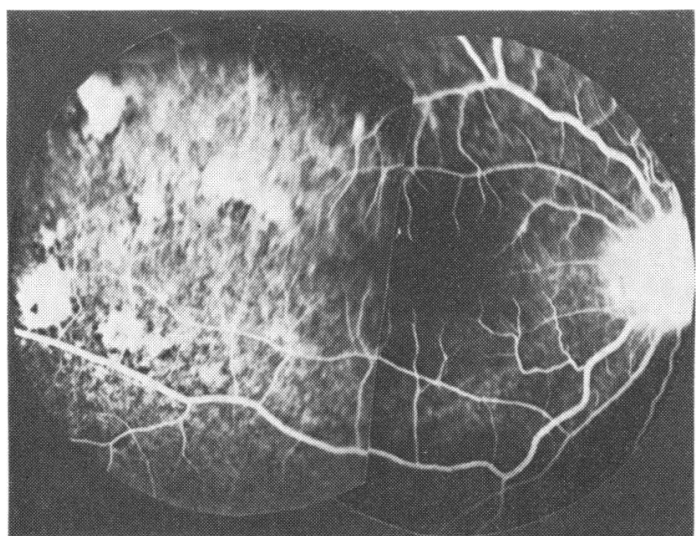

FIG. 7 Multifocal temporal lesions with leakage of dye from optic disc

were- usually similar in both eyes, but in a few patients striking asymmetry was seen. Widespread disease was not necessarily accompanied by severe morphological change, since in many fundi the entire posterior pole was affected by pigment epithelial atrophy only.

The changes observed in the fundus were as follows:

\section{Morphology}

Atrophy of the retinal pigment epithelium

In its mildest form this was represented by an illdefined area of uneven thinning of the pigment epithelium, which showed mottled hyperfluorescence on fluorescein fundus angiography (Plate $1 a$; Figs $1,9 a)$. This change alone was seen in 55 patients $(22.5$ per cent), 29 in the savanna and 26 in the rain-forest. It was sometimes difficult to identify by ophthalmoscopy, and fluorescein angiography was used as a confirmatory test whenever possible.

In its more severe form there was a well-defined greyish area of confluent atrophy of the pigment epithelium (Plates $\mathrm{I} b-d, 2 a, b, c, 3 a, b, 4 a$ ). During the initial transit of dye there was even hyperfluorescence, which faded during the subsequent Io min (Figs 2-8, I0, I I, I 3, I4). This change was seen in 93 patients $(38 \cdot I$ per cent), $5 \mathrm{I}$ in the savanna and 42 in the rain-forest.

In 2 i patients (I 4 savanna, seven rain-forest) the lesions were well defined and circular and had a metallic reflex, similar to the tapetal reflex seen in genetically-determined retinal degenerations (Mann, 1937) (Plates 3a, $b$; Figs $13 a, b$ ).

\section{Atrophy of the choriocapillaris}

This was not seen in isolation, but occurred in areas of pigment epithelial atrophy. Disappearance

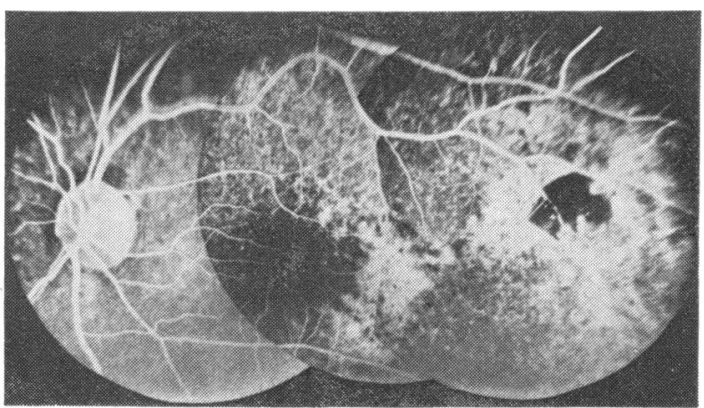

FIG. 8 Confluent atrophy of pigment epithelium temporal to fovea 

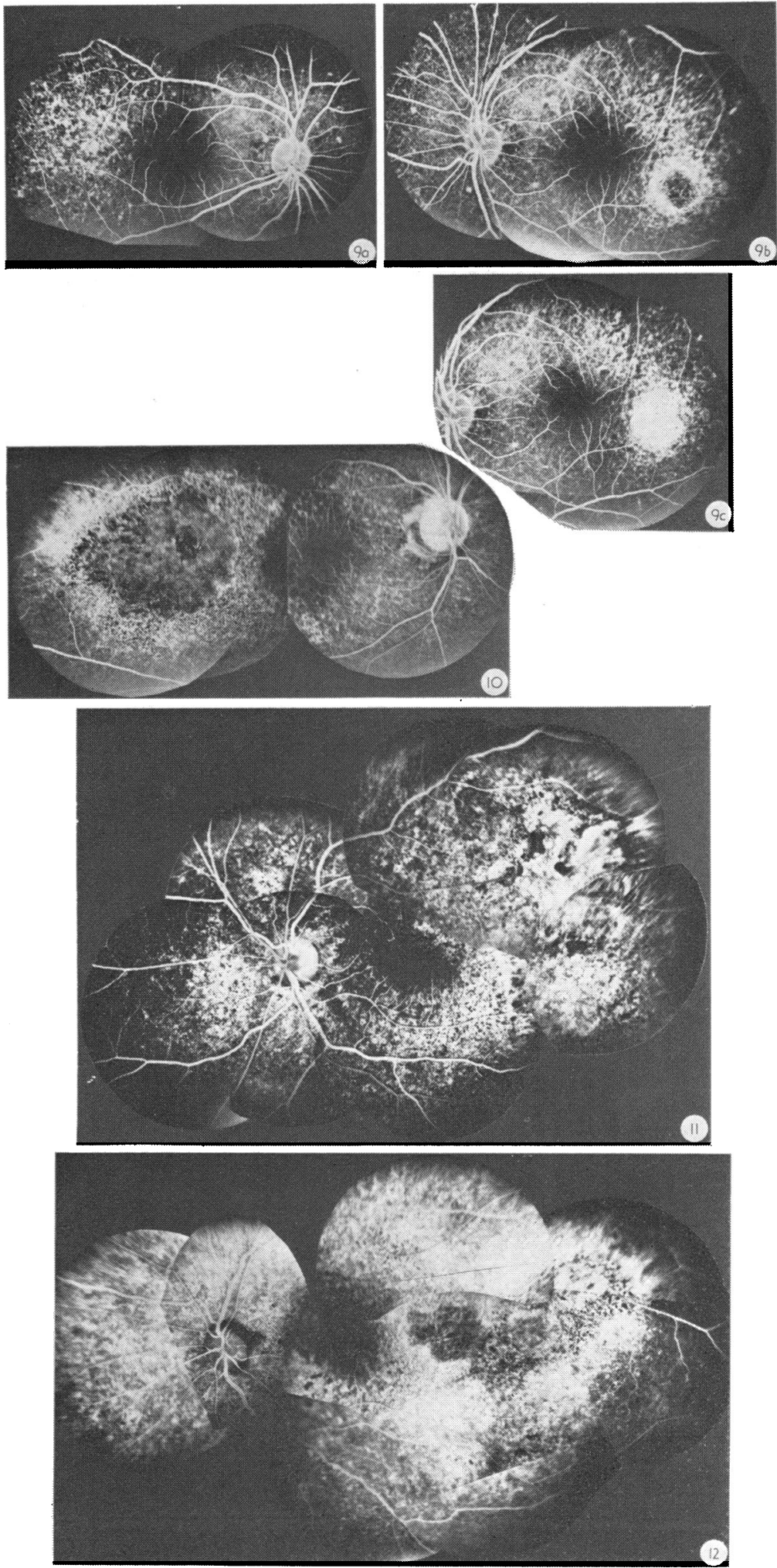

FIG. 9 Right eye shows irregular pigment epithelial atrophy temporal to fovea (9a). Fluorescein angiographv of left eye of same patient, illustrated in Plate 2a, demonstrated widespread change and focal lesion with atrophy of pigment epithelium and choriocapillaris (9b). Five minutes after initial dye entry, central portion was hyperfluorescent (9c)

FIG. 10 Fluorescein angiography of right eye illustrated in Plate $2 \mathrm{~b}$, demonstrating confluent atrophy of the pigment epithelium temporal to fovea

FIG. I I Fluorescein angiography of left eye illustrated in Plate 2c demonstrating atrophy of pigment epithelium and choriocapillaris temporal to fovea, and widespread atrophy of pigment epithelium only in remainder of posterior pole

FIG. I 2 Fluorescein angiography of left eye illustrated in Plate $2 \mathrm{~d}$ demonstrating atrophy of pigment epithelium and choriocapillaris temporal to fovea, and widespread atrophy of pigment epithelium only in remainder of posterior pole 


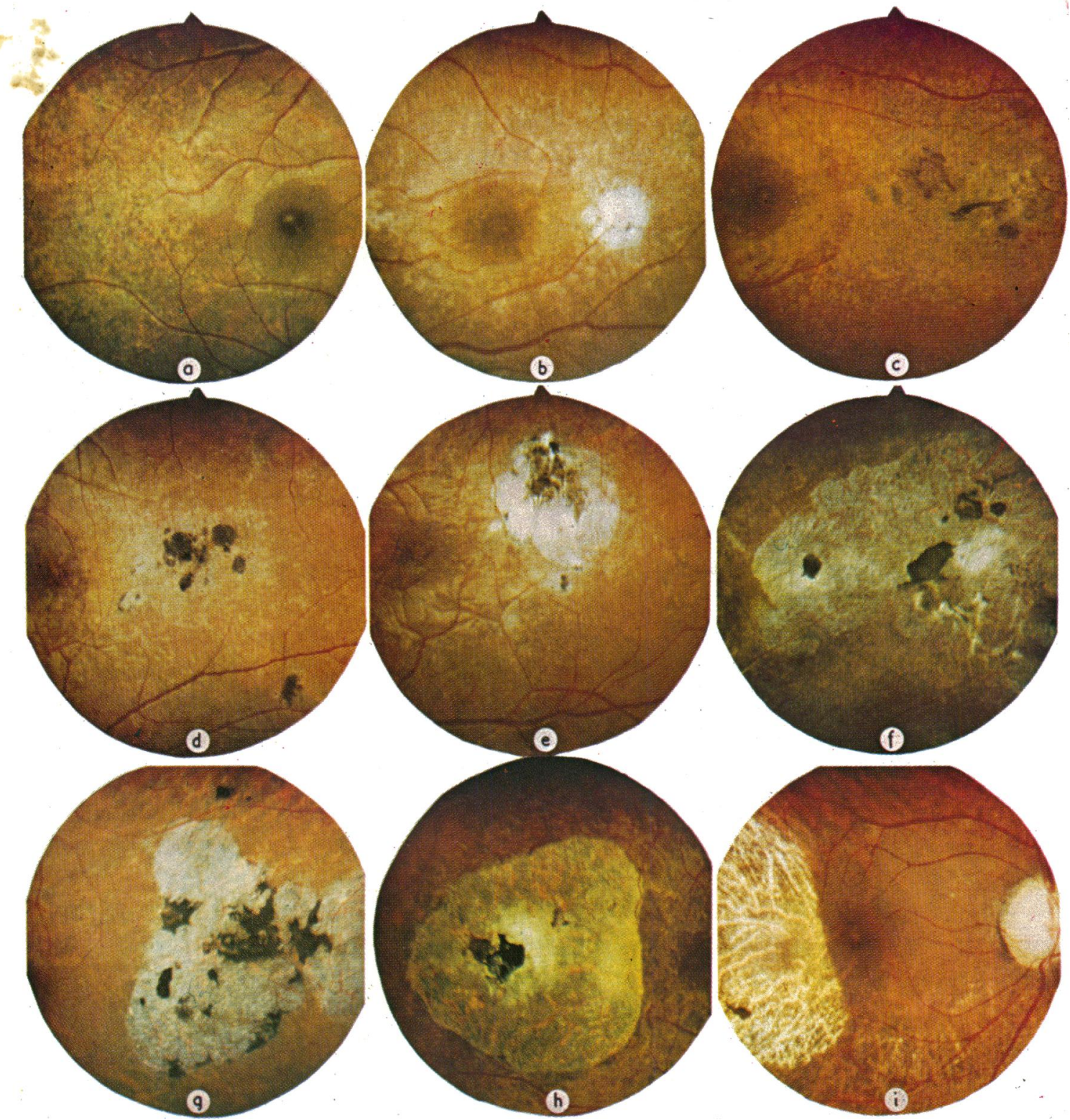

PLATE I Lesions temporal to fovea comprising pigment epithelial mottling (1a), confluent atrophy of pigment epithelium (I b, c, d, e) and combined atrophy of pigment epithelium and choriocapillaris (If, i)

of the choriocapillaris allowed a direct view of the large choroidal blood vessels, which occasionally appeared to be white rather than red (Plates if $f-i$, $2 a, 4 a-d)$. Fluorescein angiography (Figs $9 b, c$, I I, I2, I $3 a, 14-16$, I 8, I $9 a-d, 20,21$ ) confirmed closure of the choriocapillaris and showed that all of the large choroidal vessels were patent, indicating that the white appearance was due to thickening of the vessel wall rather than to vessel closure. Atrophy of the choriocapillaris was seen in 50 patients $(20.5$ per cent), 29 in the savanna and $2 \mathrm{I}$ in the rain-forest. Confluent atrophy of the pigment epithelium and choriocapillaris affecting the whole of the posterior fundus was seen in eight patients only (Plate $4 d$; Fig. 20). In large areas of atrophy of this type, islands of surviving choriocapillaris could often be demonstrated by angiography (Fig. 2I). This change was most frequently seen in a part of the posterior pole, which was otherwise diffusely diseased (Plates 

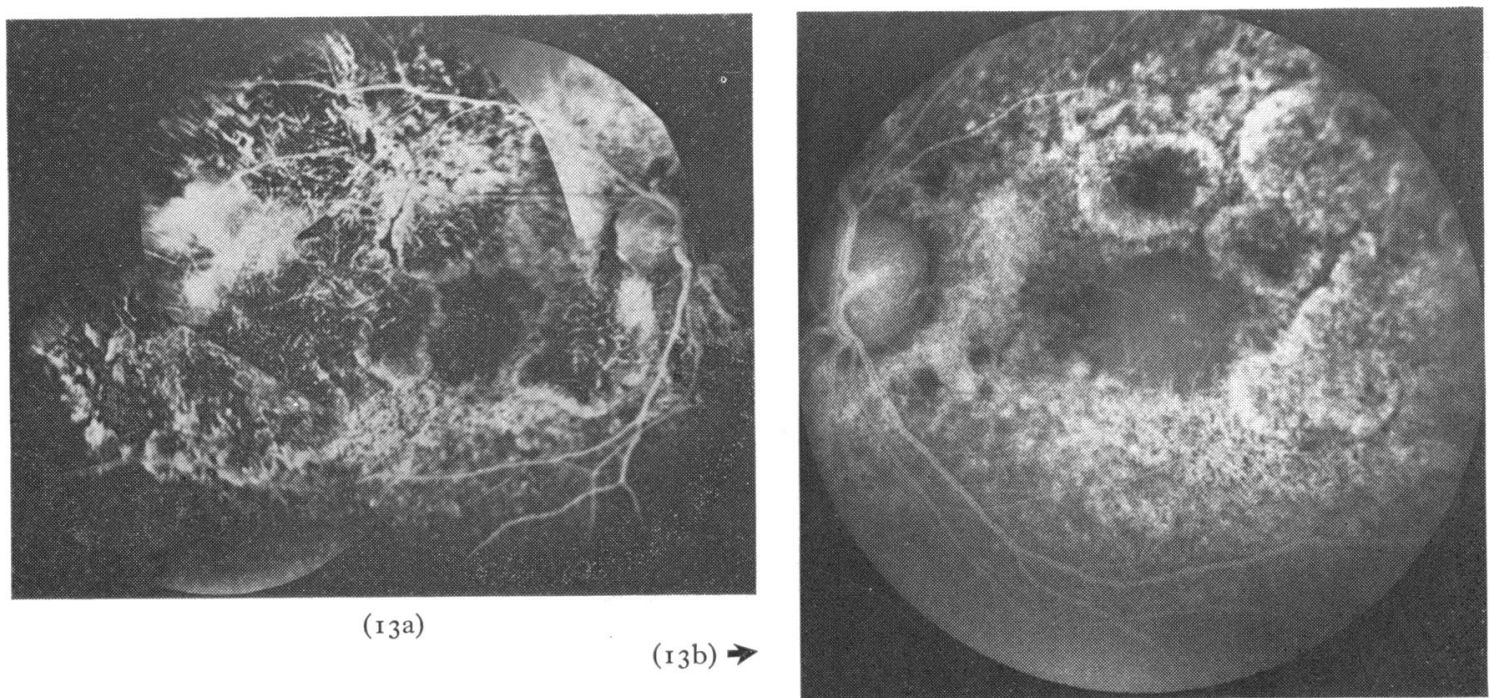

FIG. I3 Fluorescein angiography of right eye illustrated in Plate 3 a demonstrating well-defined circular areas of pigment epithelial atrophy throughout posterior pole, but sparing fovea (13a). There is atrophy of choriocapillaris above and temporal to fovea with leakage of dye from subretinal fibrous tissue. Left eye of same patient (Plate $3 \mathrm{~b})$ shows similar disease $(13 \mathrm{~b})$

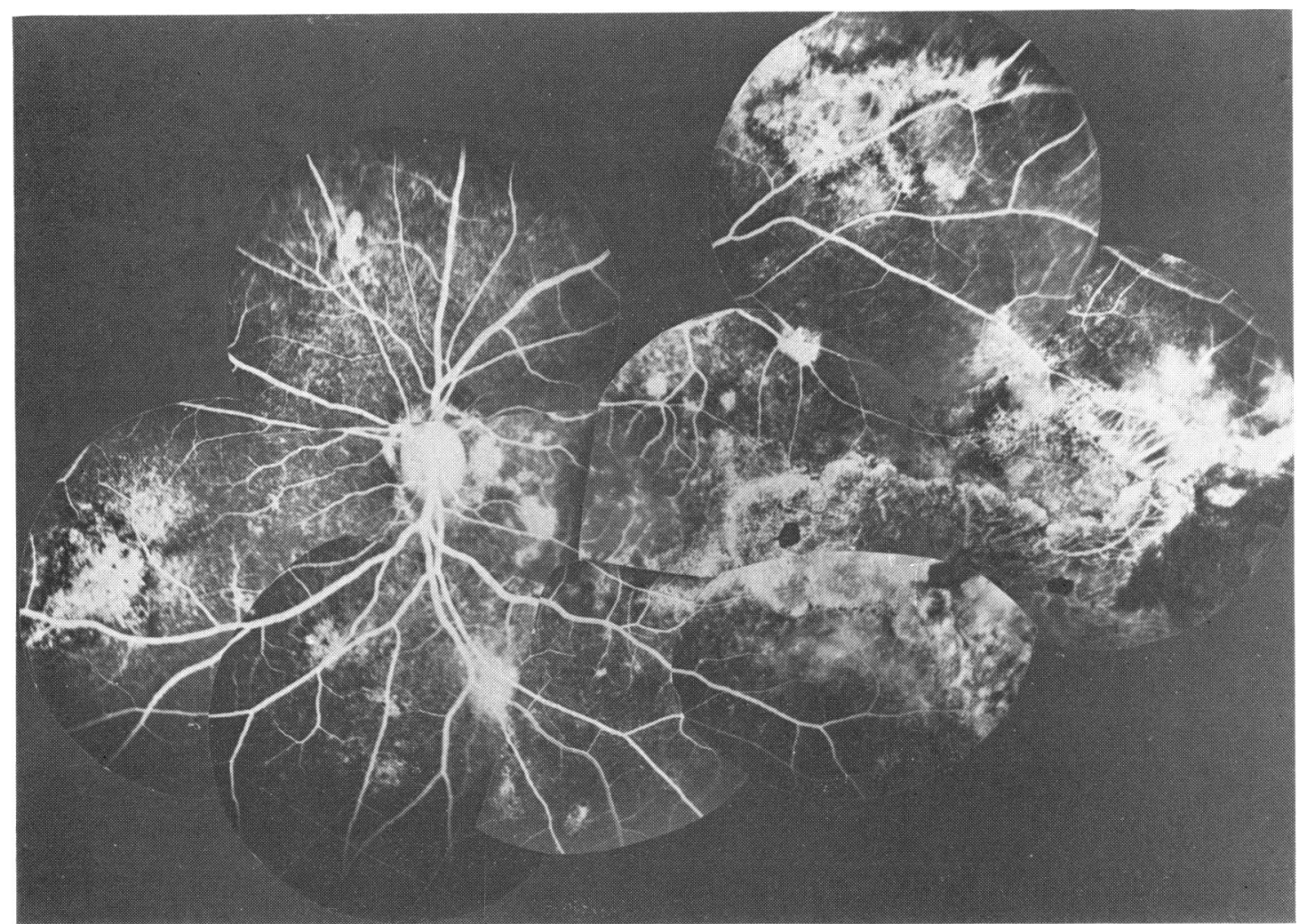

FIG 14 Multifocal disease comprising localized atrophy of pigment epithelium throughout posterior pole, and confluent atrophy of pigment epithelium and choriocapillaris temporal to fovea (Temporal lesion shown in Plate If) 


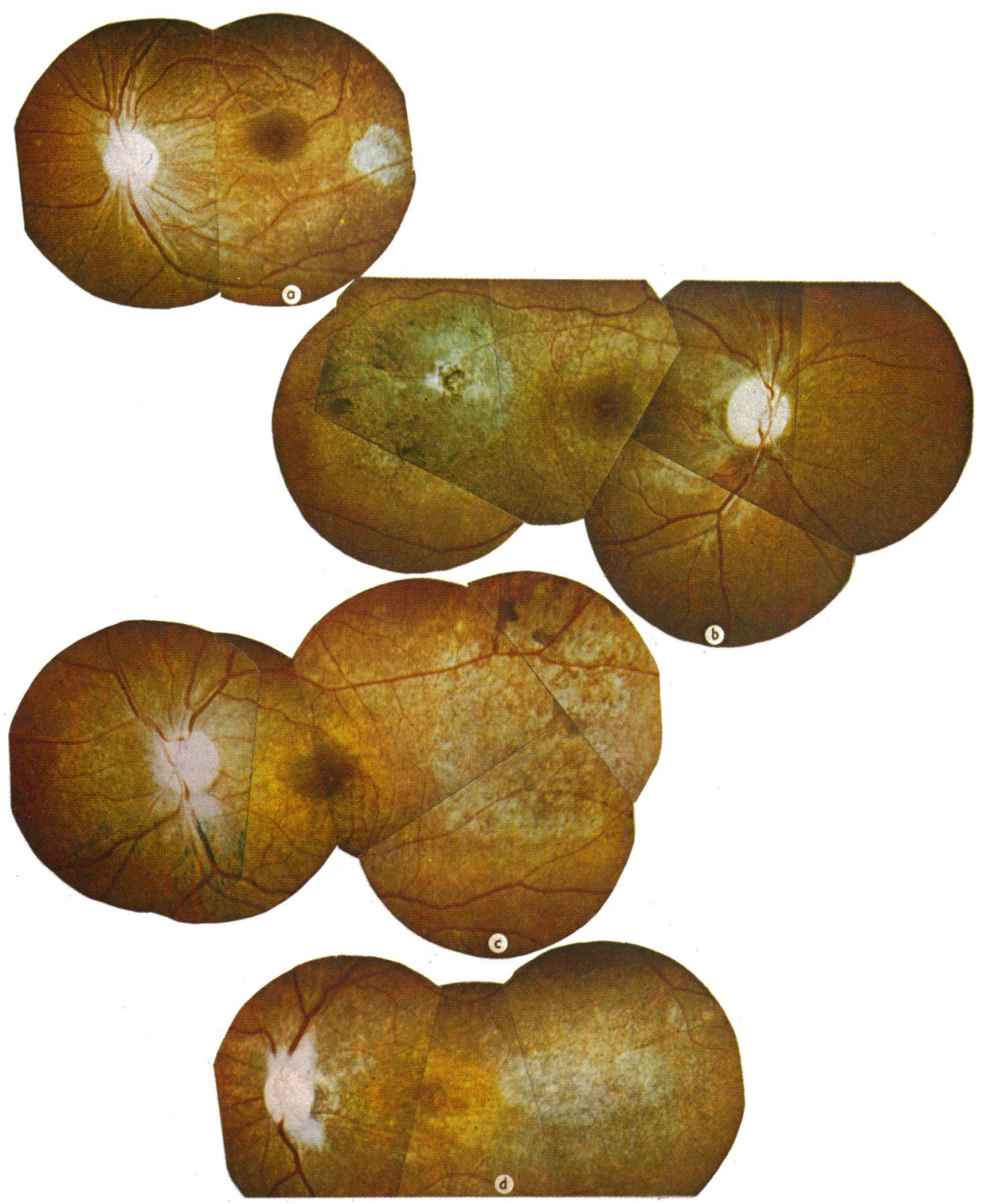

PLATE 2 Lesions temporal to fovea consisting of confluent atrophy of pigment epithelium (2a-d). In one patient (2d) there is peripapillary fibrosis

I $h, i, 2 a, 3 c, 4 a, b$; Figs $9 b-c$, 10-19). These patches were hypofluorescent during the initial transit of dye due to lack of choriocapillaris, but when small became hyperfluorescent after 5 min (Figs $9 b, c$ ).

Ill-defined pale swelling at the level of the choroid and pigment epithelium

Lesions of this type occurred in areas of diffuse disease, and were identified in 14 patients $(5.7$ per cent) eight in the savanna and six in the rain- forest. Fluorescein angiography showed these lesions to be highly vascular, and after initial dye transit there was progressive leakage of dye into the lesion (Figs 1 $9 a-d, 2$ I).

Subretinal fibrosis with widespread atrophy of the retinal pigment epithelium and choroid

This deep lesion was white with well-defined borders and occurred in $2 \mathrm{I}$ patients $(8.6$ per cent), nine in the savanna and 12 in the rain-forest 


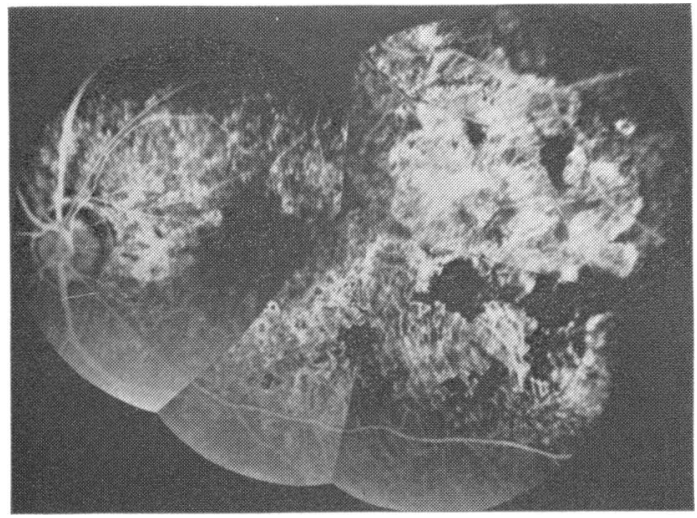

FIG. I 5 Confluent atrophy of pigment epithelium and choriocapillaris temporal to fovea

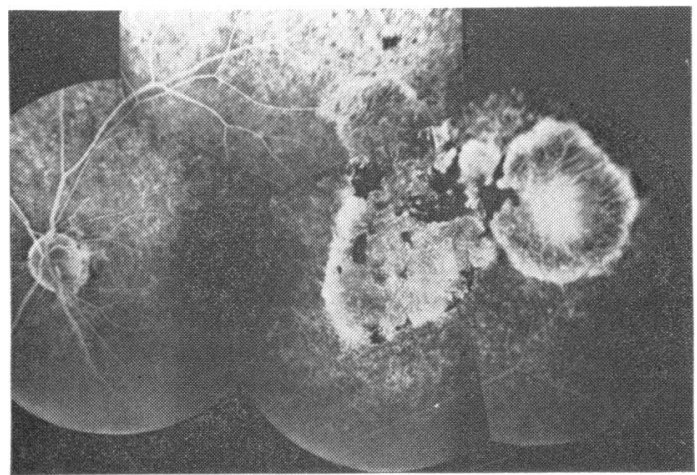

FIG. I6 Confluent and well-defined atrophy of pigment epithelium and choriocapillaris temporal to fovea

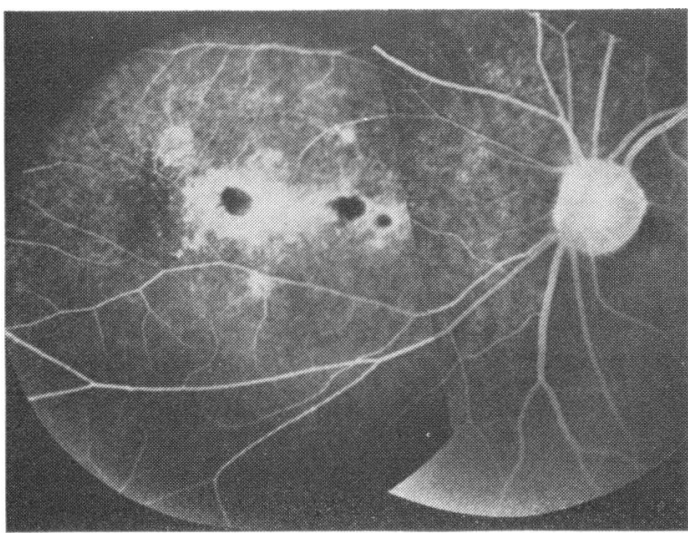

FIG. 7 Isolated nasal lesion comprising confluent atrophy of pigment epithelium
(Plates $3 a-d)$. Fluorescein angiography indicated the presence of capillaries within the fibrous tissue (Figs I3 $a$, 16, 21).

\section{Hyperpigmentation at the level of the pigment epithelium}

This was common to all forms of atrophy of the retinal pigment epithelium and choriocapillaris, and was never seen in isolation. It presented as brown or mauvish-brown spots or discs, uniformly distributed throughout the area of choroido-retinal atrophy (Plate $1 c$; Figs $2,3,4,5$ ), or as irregular hyperpigmentation in any part of the lesion (Plates $1 d-i, 2 b-d, 3 a-d, 4 a-b$; Figs $6-8$, 10-18). In two patients the changes were widespread, and gave rise to the appearance of pigmentary retinopathy (pseudoretinitis pigmentosa). On fluorescein angiography the pigment obscured the background choroidal fluorescence.

Pigment migration forwards into the retina was relatively uncommon. It presented as solid-black masses, or more rarely as 'bone corpuscle' and retinal paravascular pigmentation.

\section{Posterior retinal oedema and uveitis}

In three patients who had severe uveitis with a cellular reaction in the aqueous and vitreous humours, the posterior retina was oedematous. On fluorescein angiography there was dye leakage into the retina from the retinal capillaries and veins (Figs 22a, b, c).

\section{Distribution}

The most common site of fundus disease was temporal to the fovea (Plates $1 a-i, 2 a-d, 3^{b-d}$, Figs $1-2,6-10,12,13 b, 15,16,18)$. Lesions at this site were seen in 135 patients $(55.3$ per cent $), 76$ in the savanna and 59 in the rain-forest. Isolated lesions nasal to the optic disc were relatively less common, presenting in only 18 patients $(7 \cdot 4$ per cent), Io in the savanna and eight in the rainforest (Plate $4 a$; Figs 17, 18). Marked peripapillary pigmentary atrophy was seen in 22 patients (9.0 per cent), I4 in the savanna and eight in the rain-forest. While some patients had isolated lesions at these sites, others had multiple welldefined lesions in the posterior fundus which frequently formed an interrupted ring around the macular region (Fig. 14). The entire posterior pole was involved in 63 patients $(25.8$ per cent), 36 in the savanna and 27 in the rain-forest (Plates $3 c, 4 b-d$, Figs $4,5,11-13 a, 19-21)$. In 38 of them (22 in the savanna and 16 in the rain-forest), the macular region was spared (Plates $3 a, c, 4 c$; Figs $4,5,13 a, 19 a)$. 


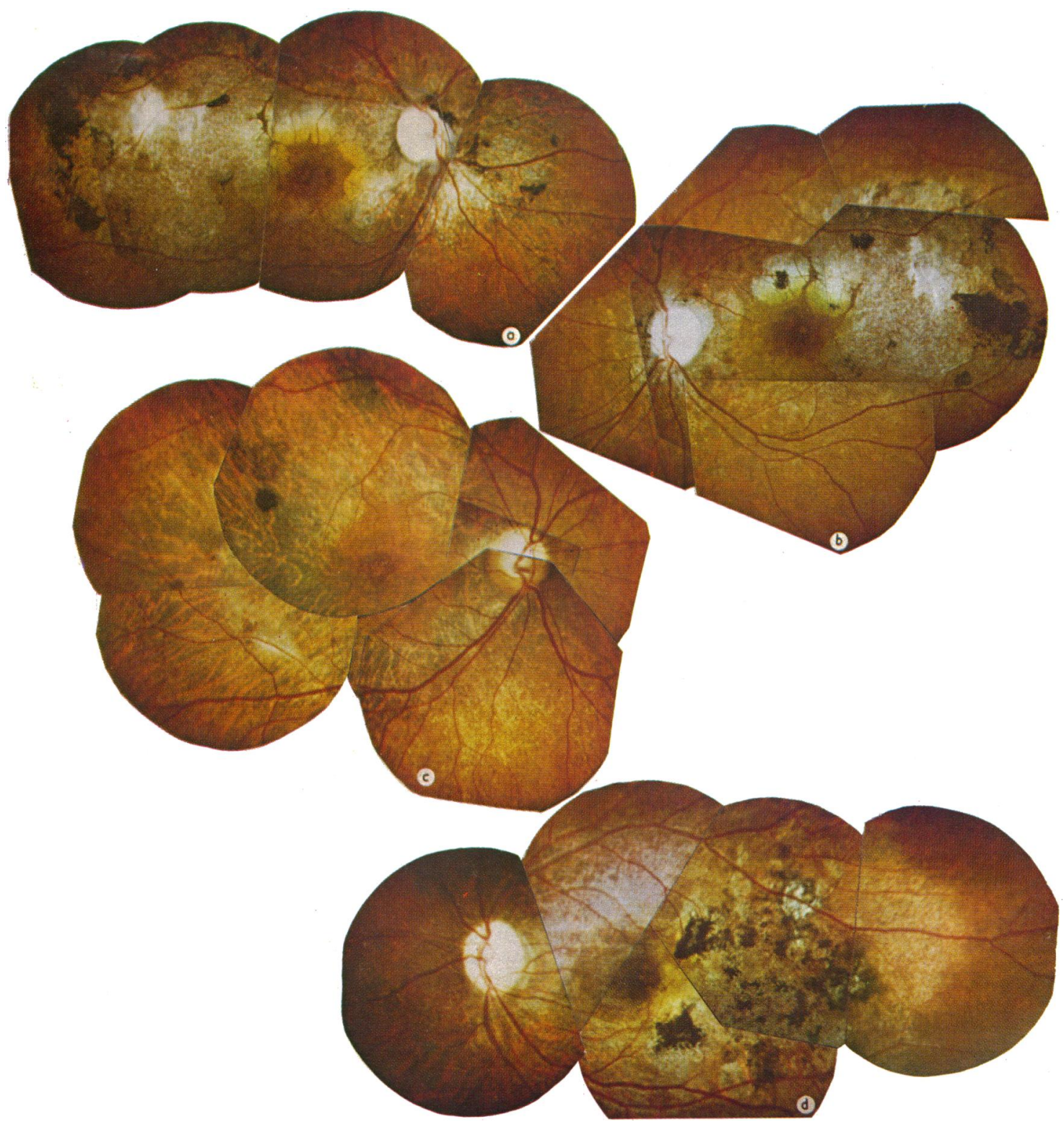

PLATE 3 Widespread confluent atrophy of pigment epithelium occurring as well-defined lesions (3a, b), as diffuse atrophy occupying whole of posterior pole but sparing macula $(3 \mathrm{c})$ and in temporal region associated with marked hyperpigmentation (3d). In all four patients there was localized subretinal fibrosis

\section{OPTIC DISC CHANGES}

Optic atrophy was present in 148 patients $(60 \cdot 6$ per cent), 78 in the savanna and 70 in the rainforest. In each case retinal nerve fibre loss was indicated by defects in the superficial retinal white reflex, and baring of the retinal blood vessels was apparent (Hoyt, Frisen, and Newman, 1973) (Fig. 23). Pronounced sheathing of the major retinal vessels on the optic disc and extending I to 2 disc diameters away from the disc was present in 39 of these patients ( 19 in the savanna and 20 in the rain-forest) (Plate $2 d$; Fig. 26), and in three there was marked peripapillary hyperpigmentation.

In 137 ( 92.6 per cent) of the patients with optic atrophy there were associated choroido-retinal changes compatible with onchocerciasis, but in most of these the fundus changes were mild and it was unlikely that the atrophy was consecutive to 
retinal disease. By contrast, severe choroido-retinal atrophy affecting the entire posterior pole was seen without optic atrophy in nine patients.

Swelling of the optic disc was seen in 49 patients (20.1 per cent), 37 in the savanna and 12 in the rain-forest, of whom 29 had choroido-retinal lesions compatible with onchocerciasis. Fluorescein angiography was performed in 37 of these cases and this showed dilatation of the superficial capillaries of
FIG. I8 Fluorescein angiography of left eye illustrated in Plate $4 \mathrm{a}$ demonstrating focal lesions temporal and nasal to fovea comprising atrophy of pigment epithelium and choriocapillaris

FIG. 19 Fluorescein angiography of right eye illustrated in Plate $4 \mathrm{~b}$ demonstrating combined atrophy of pigment epithelium and choriocapillaris temporal to fovea, and confluent atrophy of pigment epithelium elsewhere in posterior pole but sparing macula (19a). Central part of this area had subretinal vascular lesion $(\mathrm{19b}, \mathrm{c})$ from which there was profuse leakage of dye (19d)

FIG. 20 Fluorescein angiography of right eye illustrated in Plate $4 \mathrm{~d}$ demonstrating confluent atrophy of pigment epithelium and choriocapillaris throughout posterior pole the optic disc and peripapillary retina, with leakage of dye into the nerve head (Figs I, 3, 5-7, I0, I I, 24, 25).

\section{VISUAL FUNCTION}

The visual acuity of each eye is shown for savanna and rain-forest patients separately in Table III.

Many patients had good central vision, and the 


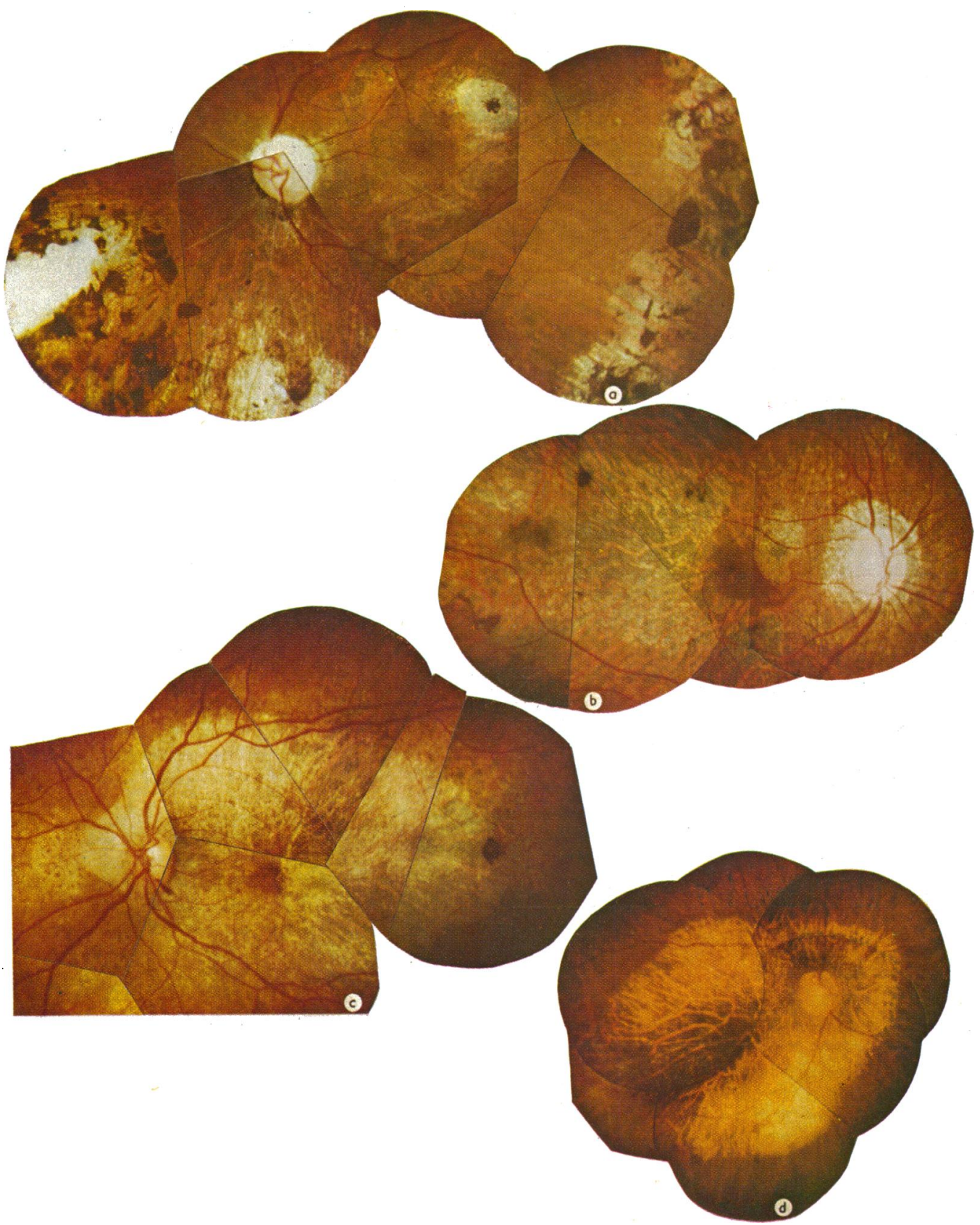

PLATE 4a Widespread focal disease in which temporal lesion consists of confluent atrophy of pigment epithelium and nasal lesion shows combined atrophy of pigment epithelium and choriocapillaris

b Confluent atrophy of pigment epithelium and choriocapillaris temporal to macula. $W$ thin this area there is vascular subretinal lesion

c Confluent atrophy of pigment epithelium occupying whole of posterior pole but sparing macula and accompanied by atrophy of choriocapillaris temporally and superiorly

d Confluent atrophy of pigment epithelium and choriocapillaris affecting whole of posterior pole 


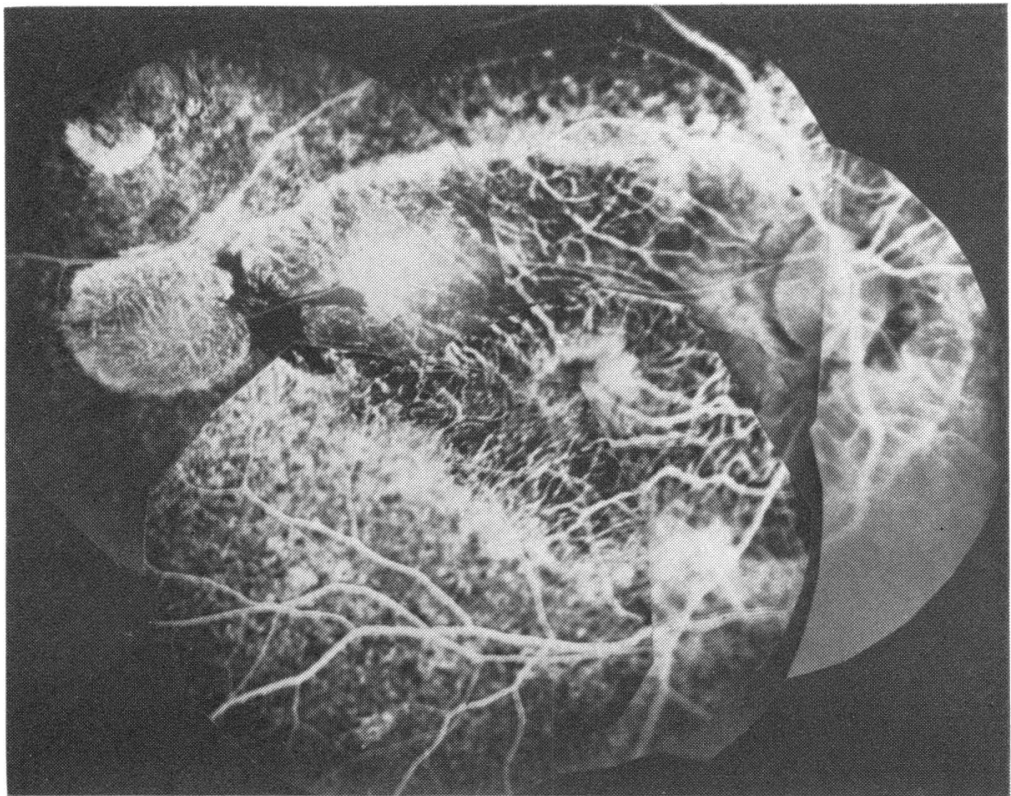

FIG. 2 I Fluorescein angiography. demonstrating confluent atrophy of pigment epithelium and choriocapillaris throughout the posterior pole except in temporal part of lesion where choriocapillaris survives. Within area is subretinal vascular lesion with dye leakage

median visual acuity in each group was 6/12. However, it must be emphasized that most patients had symptoms related to visual field loss and poor night vision, and on examination were found to have very restricted visual fields, so that many with good central visual acuity were severely handicapped.

Table III Visual acuity by area

\begin{tabular}{|c|c|c|c|c|}
\hline \multirow{3}{*}{$\begin{array}{l}\text { Visual } \\
\text { acuity }\end{array}$} & \multicolumn{2}{|l|}{ Savanna } & \multicolumn{2}{|l|}{ Rain-forest } \\
\hline & $\begin{array}{l}\text { Right } \\
\text { eye }\end{array}$ & $\begin{array}{l}\text { Left } \\
\text { eye }\end{array}$ & $\begin{array}{l}\text { Right } \\
\text { eye }\end{array}$ & $\begin{array}{l}\text { Left } \\
\text { eye }\end{array}$ \\
\hline & No. cent $)$ & No. cent $)$ & No. $\begin{array}{c}(\mathrm{Per} \\
\text { cent })\end{array}$ & $\begin{array}{r}\text { (Per } \\
\text { No. cent })\end{array}$ \\
\hline $6 / 6$ & $56(40)$ & $53\left(3^{8}\right)$ & $34(33)$ & $36(35)$ \\
\hline $6 / 9$ & 12 (9) & I I (8) & $16(15)$ & I3（12） \\
\hline $6 / 12$ & I 5 (I I ) & $23(16)$ & $7 \quad(7)$ & $3 \quad(3)$ \\
\hline $6 / 18$ & $9 \quad(6)$ & $7 \quad(5)$ & $6 \quad(6)$ & $5 \quad(5)$ \\
\hline $6 / 24$ & $6 \quad(4)$ & 3 (2) & $5 \quad(5)$ & $9 \quad(9)$ \\
\hline $6 / 36$ & 3 (2) & $7 \quad(5)$ & $3 \quad(3)$ & I (I) \\
\hline $6 / 60$ & $2 \quad(2)$ & $3 \quad(2)$ & $2(2)$ & $4 \quad(4)$ \\
\hline $\begin{array}{l}\text { Counting } \\
\text { fingers } \\
\text { Hand }\end{array}$ & $8 \quad(6)$ & (6) & $3 \quad(3)$ & $7 \quad(7)$ \\
\hline $\begin{array}{l}\text { movements } \\
\text { Perception of } \\
\text { light }\end{array}$ & I 2 (9) & (9) & I I (I I) & I I (I I ) \\
\hline Present & (6) & $3 \quad(2)$ & 2 (2) & (6) \\
\hline Absent & (6) & $9 \quad(6)$ & I 5 (I 4) & $9 \quad(9)$ \\
\hline Total & I 40 & 140 & 104 & 104 \\
\hline
\end{tabular}

Altogether 145 patients $\left(59^{\circ} 4\right.$ per cent) had either very poor vision in both eyes, or the visual field was restricted to within $5^{\circ}$ of fixation in the better eye, so that they were severely handicapped. It was considered that in 127 of these $(87.6$ per cent) the visual loss was determined by optic nerve rather than choroido-retinal disease.

The pattern of visual loss in most patients suggested optic nerve disease. Patients with optic disc swelling were occasionally asymptomatic, but usually complained of visual field loss and poor night vision. In all patients with mild or early disease arcuate defects could be demonstrated. In all cases of established optic nerve disease, whether swelling or atrophy, there was restriction of the visual fields to within $5^{\circ}$ of fixation. Five patients had normal optic discs despite a history of recent loss of visual acuity and demonstrable arcuate defects.

\section{BLOOD TESTS}

The results of tests for treponemal disease on the 87 blood samples suitable for testing are shown in Table IV. It is likely that the positive VDRL slide tests in the presence of negative TPHA tests represented a biologically false positive result, so that there was evidence of treponemal infection in 26 patients from the rain-forest but only one in the savanna. Table V shows the type of ocular disease compared with the results of treponemal tests in the patients from the rain-forest, and demonstrates that there was no correlation between the two. 


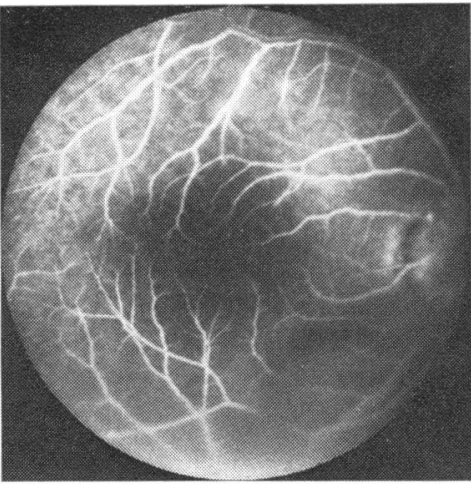

(a)

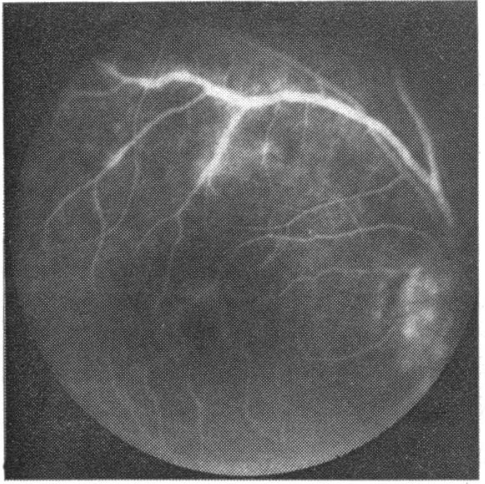

(b)

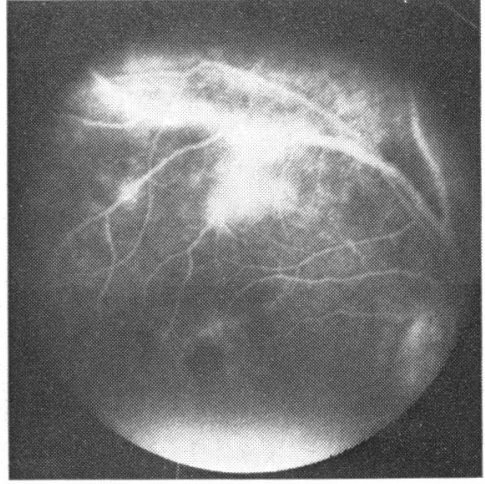

(c)

FIG. 22 Fluorescein angiography of patient with vitritis and posterior retinal oedema, demonstrating leakage from retinal veins

Only eight specimens out of the total of 93 suitable for testing had positive solubility tests for sickle haemoglobin (five from the savanna and three from the rain-forest), and electrophoresis showed all eight to contain haemoglobin $\mathrm{S}$ and $\mathrm{A}$.

Table IV Results of tests for treponemal disease

\begin{tabular}{|c|c|c|c|}
\hline $\begin{array}{l}\text { Treponema } \\
\text { pallidum } \\
\text { haemagglutinin } \\
\text { assays }\end{array}$ & $\begin{array}{l}\text { Venereal Disease } \\
\text { Reference } \\
\text { Laboratory } \\
\text { flocculation tests }\end{array}$ & Savanna & $\begin{array}{l}\text { Rain- } \\
\text { forest }\end{array}$ \\
\hline+ & + & 0 & 9 \\
\hline+ & - & I & I 7 \\
\hline- & + & 2 & 2 \\
\hline \multirow[t]{3}{*}{-} & - & 40 & I6 \\
\hline & & - & - \\
\hline & & 43 & 44 \\
\hline
\end{tabular}

Table $\mathbf{V}$ Results of test for treponemal disease compared with type of ocular disease

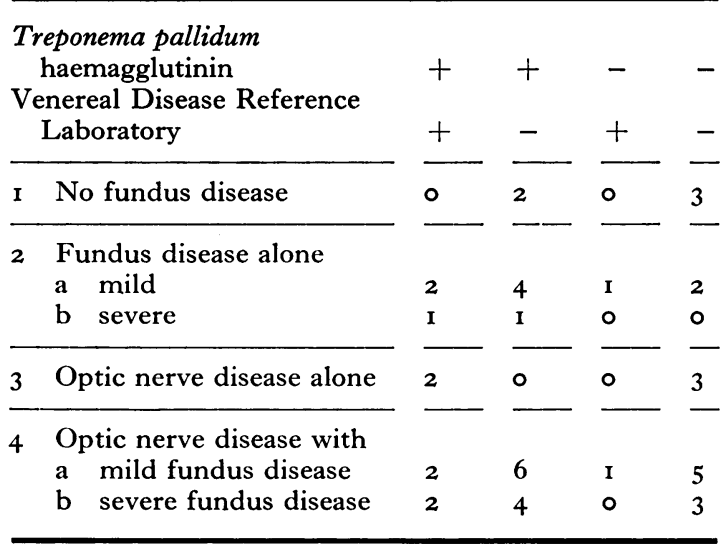

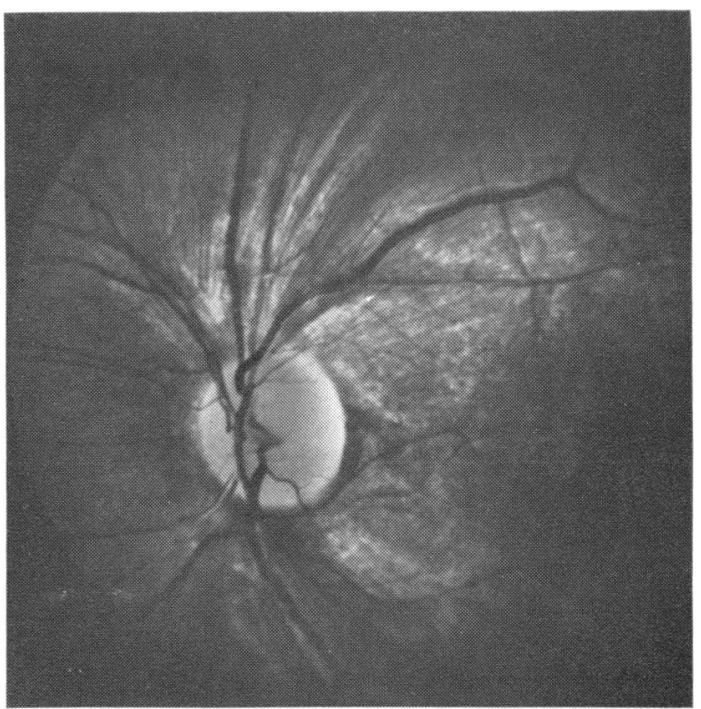

FIG. 23 Red free fundus photograph demonstrating linear defects in superficial reflex of retina indicating nerve fibre bundle loss

Fundus changes attributable to sickle cell disease were not seen in this study.

\section{Discussion}

The evidence that the posterior segment ocular lesions described in this paper are due to onchocerciasis is largely epidemiological. In the past, various workers have attempted to classify the fundus lesions of onchocerciasis into distinct clinical entities on the basis of their morphology. The best known form of the disease, consisting of well-defined atrophy of the choroid and retina, was first described by Hissette (1932) in the Congo basin and later by Bryant (1935) in Sudan. Ridley 

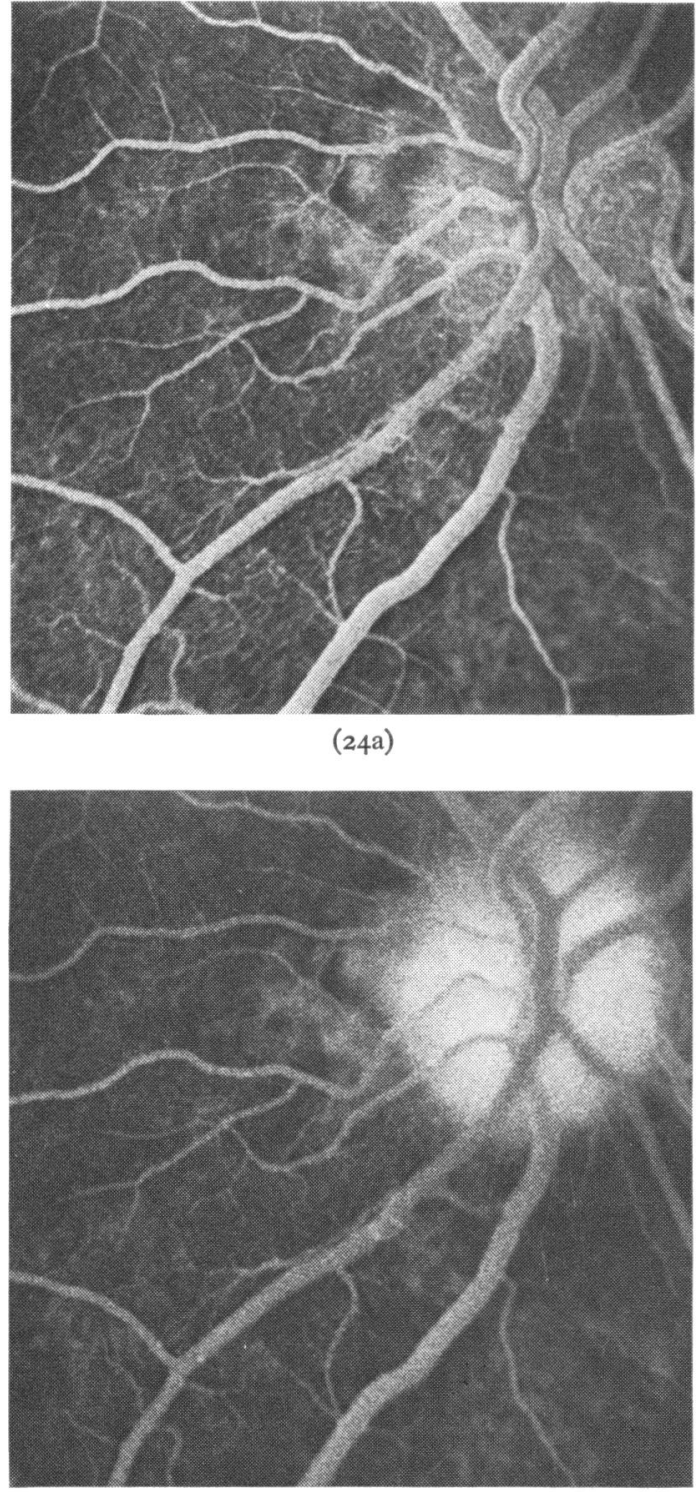

(24b)

FIG. 24 Dilatation of pre-and peripapillary blood vessels (24a) and leakage of dye into optic disc (24b)

(1945) gave the most detailed early account of this lesion in patients from West Africa, and he was not in doubt that the ocular disease was due to infection by $O$. volvulus. On the basis of his own observations and previously published histological material (Hissette, 1932; Bryant, 1935; Semadini, 1943), he thought it likely that the vascular atrophy in the choroid was due to occlusion of short ciliary blood vessels by endarteritis rather than to inflammation in the choroid. However, Neumann and
Gunders (1973), in a histopathological study of an eye with the typical changes described by Ridley, found all but one short ciliary artery supplying the diseased area to be normal. The one remaining vessel was markedly narrowed and surrounded by plasma cell infiltration, and they implied that arterial occlusion was unlikely to be important in the pathogenesis of the atrophic lesion.

Rodger (1957, 1960) distinguished two types of fundus lesion in onchocerciasis: an atrophic type, in which signs of inflammation were absent and microfilariae were not seen in the eye, and an inflammatory type, in which abundant microfilariae could be identified. He suggested that vitamin-A deficiency was important in the pathogenesis of the former.

The lack of evidence of vitamin-A deficiency in the present study is in agreement with the findings of Lagraulet (1972). Further, Neumann and Gunders ( 1963 ) found microfilariae in the anterior chamber in all patients with the atrophic lesion in Liberia, and our experience in this study supports their observations. Finally, Neumann and Gunders (1973) in their histological study found microfilariae of $O$. volvulus in the choroid at the site of atrophy.

Choyce (1958) described a disease characterized by atrophy of the retina and choroid affecting the whole of the fundus, which he thought was different from choroido-retinitis due to onchocerciasis. These patients were seen at Bonjongo, a village on Mount Cameroon, which he considered to be an isolated community, and he suggested that the disease was genetically determined, since its morphology resembled generalized choroidal atrophy previously described by Sorsby (1939, 1955). However, most authors (D'Haussy, Le Breton, Aubry, Vandendorpe, Lagraulet, Budden, Bisley, and Quarcoopome, 1958; Lagraulet, I958; D'Haussy and Uemura, 1960; Quéré and others, 1963) have been unconvinced by Choyce's claim that he was describing a disease different from onchocerciasis, and have assumed that the condition described in Bonjongo was a severe form of that described in Africa by Hissette (1932), Bryant (1935), and Ridley (1945), and in Central America by Quevedo (194I) and Clark (1947). We examined a large number of patients on Mount Cameroon, including many from the village of Bonjongo, and saw no condition, even in the blind, which was distinguishable from fundus disease attributable to onchocerciasis.

Quéré and others (1963) recognized three distinct morphological entities (atrophy of the retinal pigment epithelium and choroid, inflammatory choroido-retinitis, and pigmentary retinopathy) and they accepted that onchocerciasis alone could 

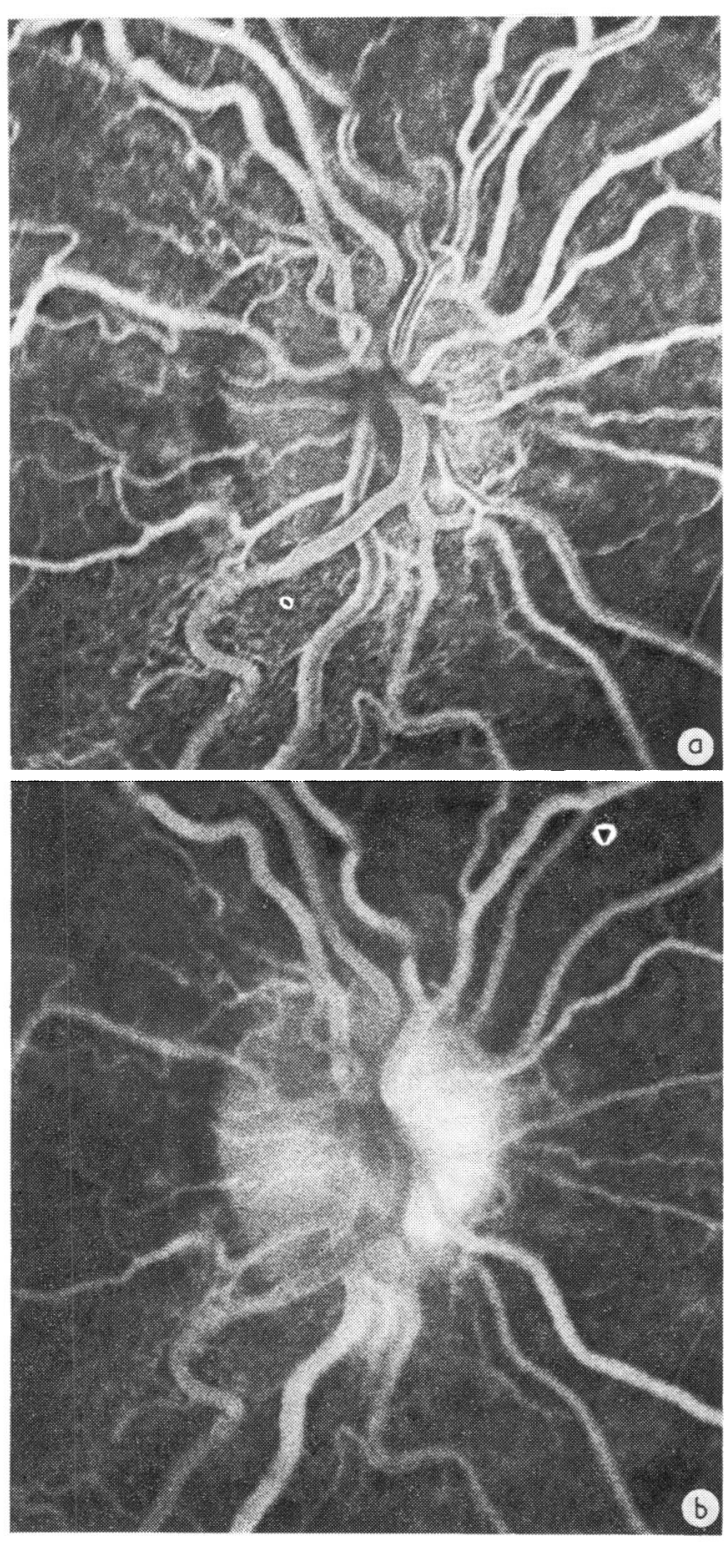

produce all three disease patterns. Metge, Chovet, Casenave, and Loréal (1974) used fluorescein fundus angiography to study the morphology of lesions in patients with onchocerciasis and they subdivided the changes into specific categories. They accepted that the different types of lesions were all due to onchocerciasis and thought that they represented different stages of severity of the disease.

In the present study, atrophy of the pigment epithelium appeared to be the mildest form of the disease, and in some cases it could be recognized with certainty only by fluorescein fundus angio-
FIG. 25 Dilated tortuous peripapillary blcod vessels (25a) and dye leakage into optic disc (25b). Other eye also had leakage into the optic disc (25c)

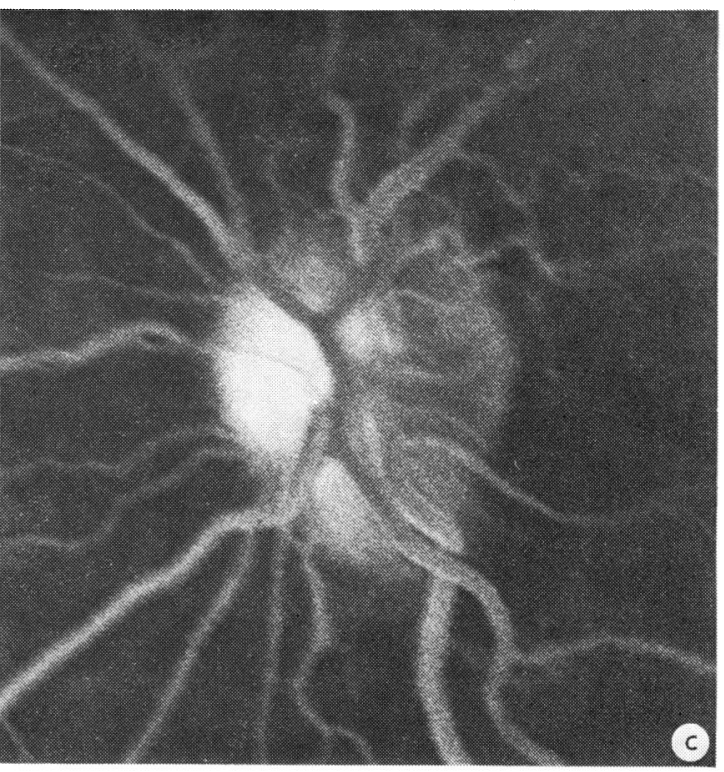

graphy. Although the histopathology of this lesion has never been studied, its co-existence with advanced choroido-retinal atrophy elsewhere in the same eye, or in the fellow eye, suggests that it is a mild or early form of the more commonlydescribed lesion characterized by confluent atrophy of the pigment epithelium and choriocapillaris.

The pale, ill-defined, swollen choroidal lesions, which proved to be vascular and showed leakage of fluorescein, are likely to be choroidal granulomata. The fact that they were seen in areas of choroido-retinal atrophy supports the view that this type of atrophy is the result of inflammation 
rather than being genetically determined (Choyce, I958). It should be pointed out that this inflammatory lesion could be recognized by ophthalmoscopy only with difficulty. Likewise, subretinal fibrosis probably results from scarring following a similar inflammatory lesion, in which invasion of the granuloma by blood vessels is prominent. The well-demarcated grey disc-shaped areas of pigment epithelial atrophy probably represent the site of previous inflammation, albeit less severe than in the vascular lesions.

Unlike Quéré and others (1963) and Metge and others (1974), we were unable to distinguish distinct forms of the disease. From the morphological standpoint, there appeared to be a continuous spectrum from mild to severe disease without any indication of demarcation between one form and another. The heterogeneity of the lesions, and the occurrence of different types of lesion in a single eye, or in the two eyes, strongly suggest that inflammation alone is responsible for the pathogenesis of fundus changes in onchocerciasis. Although the paucity of pigment-containing cells in the retina and the preservation of the outer choroid are both uncharacteristic of most postinflammatory lesions due to other infective agents, these features may be determined by the relatively low antigenicity of the microfilariae of $O$. volvulus. This would result in a low grade and localized inflammatory response associated with little necrosis, analogous to the skin changes in onchocerciasis (World Health Organization, 1974).

The severity of fundus disease in the savanna was similar to that in the rain-forest, and the differ-

ent types of lesion were seen with the same frequency in both areas (Table II). This is in contrast to the pattern of lesions seen in the cornea, where the blinding sclerosing keratitis is virtually confined to the savanna. Duke and Anderson (1972) showed that microfilariae of the Sudan-savanna strain were more pathogenic to the rabbit cornea than microfilariae of the rain-forest strain, but the present study revealed no evidence of varying pathogenicity to the human fundus.

The constancy of the distribution of choroidoretinal changes in onchocerciasis is striking, and it was recognized by Budden (1973) and Metge and others (1974) that the lesions overlie the site of scleral perforation of the long ciliary arteries. Lesions temporal to the fovea, seen in I 35 patients in this series, corresponded to the site of entry of the temporal long ciliary artery, and although lesions overlying the entry of the nasal long ciliary artery occurred, they were far less common (I 8 patients). The ring of involvement in the posterior pole with sparing of the macula, which occurred in more severe disease, overlies the ring of entry of the short ciliary arteries. The significance of this distribution could be easily understood if the microfilariae passed from the peribulbar orbital tissue into the choroid through the scleral canals as was indicated by Neumann and Gunders (1973), although the disparity between isolated temporal and nasal lesions would have to be explained. If the source of microfilariae was adult worms in the temporal region and the microfilariae gained access to the orbit through its temporal margin, it is likely that their concentration in the temporal side of the orbit would be higher than in the nasal side. It would follow that penetration by microfilariae through the temporal scleral canals would occur with greater frequency than through the canals on the nasal side. However, it has also been shown that the prevalence of $O$. volvulus microfilariae in the blood is high in heavily infected persons (Fuglsang and Anderson, 1974). If the organism causez disease by entering the eye via the blood stream, the distribution of the choroidoretinal lesions remains unexplained.

That optic nerve rather than choroido-retinal disease may be the cause of visual loss in onchocerciasis has been well recorded. Most authors agree that the optic nerve disease is inflammatory in origin, and microfilariae have been demonstrated in optic nerve tissue (Giaquinto Mira, 1934; Rodger, 1960; Paul and Zimmerman, 1970). During the active stage the nerve head is swollen (Védy and Sirol, 1971), and it later becomes atrophic with ill-defined margins and perivascular sheathing and pigmentation. D'Haussy, Boyer, and Aubert (1963) described one case in detail. 
The patient had a severely restricted visual field in one eye, altitudinal loss in the other, and poor dark adaptation in both. The electroretinogram was normal or near normal in both eyes, indicating lack of involvement of the outer retina.

Patients with optic nerve disease and a short history of visual field loss had easily demonstrable arcuate field loss, and in some the field was restricted to the central $5^{\circ}$. It is likely that the symptom of poor night vision, which is so common in patients with ocular onchocerciasis, is due in many cases to denervation of the rod-rich peripheral retina by optic nerve disease, rather than to retinal disease to which it has been almost universally ascribed. The pattern of optic nerve disease was very similar to that seen in syphilis. However, there was no correlation between the results of serological tests for treponemal infection and the type of ocular disease. Positive serological tests were found almost exclusively in patients from the rain-forest, whilst the optic nerve disease was found with equal frequency in the two groups. That the optic nerve disease is not due to syphilis is in agreement with the conclusion of D'Haussy, Pfister, Rit, and Breteau (I957) drawn from a study in Mali.

In the past, little attention has been paid to the relative importance of optic neuritis and choroidoretinitis as blinding conditions in patients with posterior segment ocular disease caused by $O$. volvulus infection. D'Haussy and others (1954) found isolated optic nerve disease in 5 per cent of 536 patients suffering from ocular onchocerciasis in Bamako, and Weyts (1956) reported a frequency of 7 per cent in patients in Zaire. A further 31 per cent of Weyts's patients had combined optic nerve disease and choroido-retinitis, but no assessment was made of the relative significance of the two lesions as a cause of visual loss.

In this study, the frequency of optic nerve disease as the cause of blindness $(87.6$ per cent) was striking. This is particularly important since optic nerve disease can cause severe and progressive visual loss leading to irretrievable blindness in early life. More than a quarter of the patients in our series were under the age of 20 years, and blindness from posterior segment disease due to onchocerciasis is not uncommon in heavily infected persons at that age. This contrasts with previous views (Lagraulet, 1972).

\section{Summary}

Posterior segment ocular lesions were examined in 244 selected patients with onchocerciasis from the Sudan-savanna and rain-forest areas of the United Cameroon Republic. Fluorescein fundus angiography was performed on 2 ro cases.

As a result of this study the following conclusions were drawn:

I. The heterogeneity of single lesions, and the occurrence of different types of lesion in a single eye or two eyes, prevented subdivision of the disease into distinct forms and suggested that inflammation alone was responsible for fundus lesions in onchocerciasis.

2. Optic nerve disease, alone or in the presence of choroido-retinal changes, was responsible for a large proportion of the blindness due to posterior segment lesions in onchocerciasis ( $87 \cdot 6$ per cent in this series).

We should like to thank Professor G. S. Nelson and Dr B. O. L. Duke for helpful criticism, and we acknowledge the help of our assistants in the United Cameroon Republic, Mr S. Ayonge and Mr C. Fisiy. We are particularly grateful to Dr Pauline O'Neill of the Department of Clinical Microbiology, Louis Jenner Laboratories, St Thomas's Hospital, London SEI, Professor R. G. Huntsman in the Department of Pathology, Lambeth Hospital, London SEI, and Dr S. Welch in the Department of Biochemistry, the London Hospital Medical College, London Er, for performing blood tests on specimens obtained during the study.

\section{References}

ANDERson, J., fuglsang, H., hamilton, P. J. S., and Marshall, T. F. DE c. (r974a) Trans. roy. Soc. trop. Med. Hyg., 68, 190

$$
\longrightarrow, \frac{}{2}, \text { and }-(\text { I 974b) Ibid., 68, } 209
$$

BEN-SIRA, I., and YASSUR, Y. (1972) Brit. F. Ophthal., 56, 61 7

BRYANT, J. (1935) Trans. roy. Soc. trop. Med. Hyg., 28, 523

BUDDEN, F. H. (1962) Brit. F. Ophthal., 46, I

$$
\text { (1963) Trans. roy. Soc. trop. Med. Hyg., 57, } 64
$$

(1973) Amer. F. Ophthal., 76, 1027

CHOYCE, D. P. (1958) Trans. roy. Soc. trop. Med. Hyg., 52, I 12

Clark, W. B. (1947) Trans. Amer. ophthal. Soc., 45, 46 I

D'HAUSSY, R., BoIthias, R., and BerTet, P. (1954) Bull. méd. A.O.F., Num. Spéc. (Nov.), p. I I 5

-, BOYer, R., and AUbert, L. (1963) Ann. Oculist. (Paris), 196, 1185

- LE BRETON, G., AUBRY, M., VANDENDORPE, A., LAGRAULET, J., BUDDEN, F. H., BISLEY, G. G., and

QUARCOOPOME, C. O. (1958) Lancet, 2, 960 


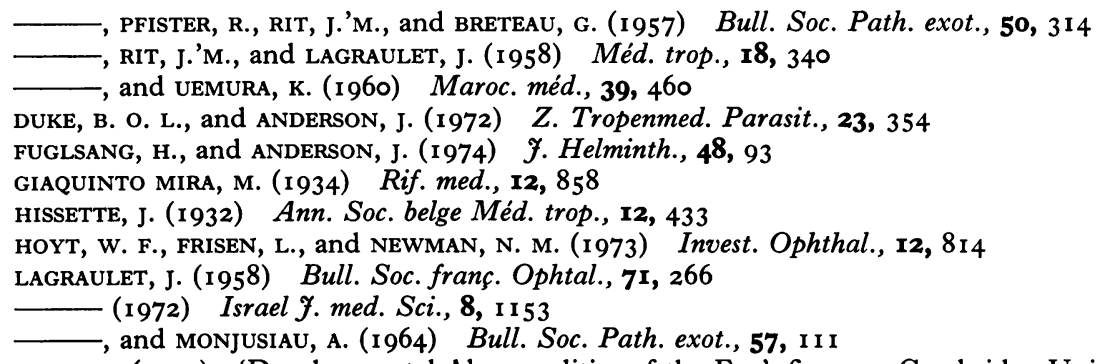

MANN, I. (1937) 'Developmental Abnormalities of the Eye', fig. 105, Cambridge University Press, London METGE, P., ChOVET, M., CASENAVE, PH., and loréal, E. (1974) Méd. trop., 34, 625

MONJUSiaU, A., LAGRAulet, J., D'HAUSSy, R., and Göckel, c. w. (1965) Bull. Wld Hlth Org., 32, 339

Neumann, E., and Gunders, A. E. (1963) Amer. F. Ophthal., 56, 573

$\longrightarrow$, and - (1973) Ibid., 75, 82

Paul, E. v., and zimmerman, L. E. (1970) Hum. Path., r, 581

QUÉRÉ, M. A., BASSET, A., LARIVIÈre, M., BASSET, M., and RAZAFinjato, R. (1963) Bull. Soc. méd. Afr. noire

Langue franc., 8, I

QUEVEDo, A. (1941) Amer. F. Ophthal., 24, I 185

RIDLEY, H. (1945) Brit. F. Ophthal., Monogr. Suppl. Io

RODGER, F. C. (1957) Ibid., 4I, 544

- (1960) Amer. F. Ophthal., 49, 327

SEMADINI, B. (1943) Schweiz. med. Wschr., 73, 75

SORSBY, A. (1939) Brit. F. Ophthal., 23, 433

- (1955) Ibid., 39, 257

toulant, P., Robineau, G., and Puyelo, R. (1950) Bull. Soc. Path. exot., 43, 61 5

vÉDY, J., and SIROL, J. (I97I) Méd. trop., 3I, 559

WORLD HEALTH ORGANIZATION (1974) 'Onchocerciasis-symptomatology, pathology, diagnosis', ed. A. A. Buck,

WHO, Geneva

WEYTS, E. J. (1956) Docum. Med. geogr. trop. (Amst.), 8, 29 